\title{
MICROSCOPIA DE FORÇA ATÔMICA APLICADA EM IMUNOENSAIOS
}

\section{Antonio Aparecido Pupim Ferreira}

Departamento de Bioquímica e Tecnologia Química, Instituto de Química, Universidade Estadual Paulista, CP 355, 14801-970 Araraquara - SP

Hideko Yamanaka*

Departamento de Química Analítica, Instituto de Química, Universidade Estadual Paulista CP 355, 14801-970 Araraquara - SP

Recebido em 4/1/05; aceito em 3/5/05; publicado na web em 24/8/05

\begin{abstract}
ATOMIC FORCE MICROSCOPY APPLIED TO IMMUNOASSAYS. Affinity reactions have been used for specific detection of their complementary partners and an enormous variety of enzyme-linked immunosorbent assay (ELISA) formats are used in research and in routine serological tests. With the advent of the atomic force microscopy (AFM) technique, the immune reactions have been monitored by these devices. In the present article we focus on applications of AFM to immunoassays. After introducing the basic concepts of AFM, a brief discussion on the monitoring of the interactions between antigens and antibodies through both topographic image and biosensor systems is presented.
\end{abstract}

Keywords: atomic force microscopy; antigen-antibody; immunoassay.

\section{INTRODUÇÃO}

Nos últimos anos a construção de biossensores ${ }^{1,2}$ tem despertado considerável interesse no monitoramento de analitos nas áreas biológica, clínica ${ }^{3,4} \mathrm{e}$ industrial ${ }^{5}$, como também no monitoramento e controle de alguns poluentes ambientais ${ }^{6}$. O crescente emprego de biossensores deve-se à possibilidade destes atenderem algumas exigências que os métodos clássicos de análises não conseguem, sendo as características mais relevantes: simplicidade de construção, resposta rápida, redução de custo, seletividade, sensibilidade, miniaturização, precisão, facilidade de uso e pequeno volume de amostra.

Um biossensor pode ser definido como um dispositivo de detecção, contendo um componente biológico ativo (enzimas, anticorpos, antígenos, células, etc.) diretamente acoplado à superfície de um transdutor, o qual converte um sinal biológico em sinal elétrico.

Com base no reconhecimento do sinal de interesse pelo detector encontram-se, por ex., os imunossensores e sensores enzimáticos. Enquanto nos biossensores com enzima são monitoradas as concentrações de substratos, produtos ou mediadores, nos imunossensores ${ }^{7-9}$, que são dispositivos analíticos, baseados nos princípios de imunoensaios heterogêneos e nos eventos físico-químicos, são resultantes da reação de afinidade antígeno-anticorpo $(\mathrm{Ag}-\mathrm{Ac})$.

No imunoensaio, o sítio combinatório do anticorpo (Ac) ou paratopo interage especificamente com porções mais superficiais (determinantes antigênicos ou epitopos) do antígeno (Ag) ou hapteno (substância não protéica de baixo peso molecular que pode se ligar a sítios específicos de combinação de anticorpos, mas não pode, por si só, iniciar uma resposta imune), formando um complexo Ag-Ac, conforme a Equação 1. Esta interação é caracterizada por uma constante de afinidade que é função das concentrações do complexo formado, do antígeno e do anticorpo livres no meio de reação. Essa interação é mantida por forças fracas, como forças iônicas, ligações de hidrogênio, forças eletrodinâmicas (van der Waals) e hidrofóbicas, garantindo o fe-

*e-mail: hidekoy@iq.unesp.br nômeno da especificidade antígeno-anticorpo. Também podem ocorrer reações não-específicas (reações cruzadas) de outros anticorpos que competem pela ligação com o antígeno ${ }^{8,10}$, como, por ex., ligação com o antígeno ${ }^{8,10}$.

$\mathrm{Ac}+\mathrm{Ag} \leftrightarrow \mathrm{Ag}-\mathrm{Ac}$

A formação do complexo (Ag-Ac) pode ser monitorada diretamente (sem a presença de marcador) ou pelo método indireto (com a presença de marcadores). Tanto o antígeno quanto o anticorpo podem ser marcados (conjugados) e as enzimas, atualmente, são os marcadores mais empregados em imunoensaios. Um dos grandes avanços em técnicas imunoanalíticas foi o desenvolvimento de enzima-imunoensaios como a denominada ELISA ("Enzyme Linked Immunosorbent Assays"), tendo enzima como meio alternativo de detecção ${ }^{11}$.

A invenção da microscopia de força atômica (AFM) foi o primeiro exemplo de método de análise micrométrica e tornou possível o emprego do cantilever em aplicações topográficas com alta resolução a dimensões reduzidas e não-topográficas (sensores com mecanismo de transdução mecânica) $)^{12-15}$. Na obtenção de imagens topográficas, é empregada uma sonda constituída de uma fina ponteira ("tip") acoplada a um cantilever, para fazer o rastreamento da superfície da amostra. A deflexão do cantilever é a resposta das forças de interações atômicas entre a ponteira e o substrato. Com o método de análise micromecânica a partir da AFM, foram desenvolvidos sensores para estudar as forças envolvidas nas interações moleculares, tendo como trandutor o cantilever. As forças de interações entre moléculas da superfície da amostra com moléculas imobilizadas na ponteira resultam na deflexão do cantilever, o qual atua como um transdutor de força.

Neste trabalho serão discutidos os monitoramentos de imunoensaios através de imagens topográficas obtidas por AFM e biossensores baseados na utilização do microcantilever do microscópio de força atômica como transdutor.

\section{MICROSCOPIA DE FORÇA ATÔMICA (AFM)}

Por muitos anos os pesquisadores tentaram conciliar a alta re- 
solução da microscopia eletrônica de varredura e de transmissão com a capacidade de se obter imagens em meio aquoso, própria dos microscópios ópticos.

Com a introdução da técnica conhecida como microscopia de tunelamento ("Scanning Tunneling Microscopy - STM") por Binnig e Rohrer, em 1981, surgiram as técnicas nanométricas ${ }^{15}$. O STM pode produzir imagens somente de superfícies de substâncias que conduzem elétrons, ou seja, a propriedade medida é a corrente túnel que flui entre a ponta fixada no cantilever e a amostra metálica como produto da diferença de potencial aplicada entre ambas. Com base nesta idéia, Binnig, Quate e Gerber inventaram, em 1986, o microscópio de força atômica ("Atomic Force Microscopy" - AFM), também conhecido como SFM ("Scanning Force Microscopy"), que pode produzir imagens de superfícies não condutoras e condutoras ${ }^{16-18}$. Estas técnicas (STM e AFM) e seus diversos modos de operação constituem uma nova classe de instrumentos pertencentes ao grupo de microscopias chamadas SPM ("Scanning Probe Microscopy - SPMs") ${ }^{17}$.

SPMs não utilizam lentes para obtenção das imagens e não necessitam de uma fonte de luz, nem de um feixe de elétrons. Estas técnicas baseiam-se na varredura da superfície estudada por meio de sondas de dimensões muito reduzidas a distâncias muito pequenas (da ordem de alguns $\AA$ ), proporcionando uma alta resolução espacial, tanto lateral como vertical, na visualização de superfícies em nível atômico de diferentes naturezas (metais, películas orgânicas, polímeros, amostras biológicas em sistemas condutores e isolantes) e em diversos meios (vácuo, pressão atmosférica, meios líquidos $)^{19}$. Essa versatilidade confere à AFM maior aplicabilidade em relação ao STM.

O princípio de funcionamento do AFM baseia-se na varredura da superfície da amostra por uma ponta piramidal (ponteira) de alguns micra de comprimento $(100$ a $200 \mu \mathrm{m})$ e geralmente com menos de vinte nanômetros de diâmetro, integrada em um cantilever flexível. A sonda (ponteira + cantilever) é sempre o componente básico do SPM e, para alcançar resolução atômica, a ponta tem que terminar em um conjunto de átomos ${ }^{20}$. A força entre a ponta e a superfície da amostra faz com que o cantilever se aproxime ou se afaste e essa deflexão é proporcional à força de interação. Na parte superior da haste há um espelho que reflete a luz de um feixe de laser. Após a reflexão, o feixe de laser passa por uma lente e incide sobre um fotodetector (fotodiodo) de quatro quadrantes, que mede as variações de posição e de intensidade da luz produzidas pelas deflexões do cantilever (Figura 1). À medida que a ponta varre a amostra ou a amostra é deslocada sob a ponta, os diferentes tipos de "acidentes geográficos" encontrados sobre a superfície fazem com que a interação mude. As variações das interações são os fatores que provocam diferentes deflexões. Essas diferenças, captadas no detector, são armazenadas e processadas por um computador, que as transformam em imagens topográficas da superfície bi e tridimensionais. A força mais comumente associada com AFM na deflexão do cantilever é a força de van der Waals ${ }^{21}$.

A técnica de AFM, conforme apresentado na Figura 2, pode ser operada em três modos diferentes: contato, não-contato e contato intermitente ("tapping") ${ }^{16}$.

No modo contato, o cantilever é mantido a poucos ângstrons da superfície da amostra e a força interatômica entre a ponta e a amostra é repulsiva. Neste modo de operação, a ponta faz um leve "contato físico" com a amostra produzindo imagens com alta resolução, mas a compressão e as forças geradas, entre a ponta e a superfície, podem causar danos à amostra, o que é especialmente prejudicial às amostras biológicas que são sensíveis e nem sempre fortemente aderidas ao substrato.

No modo de não-contato, o cantilever é mantido de dezenas a

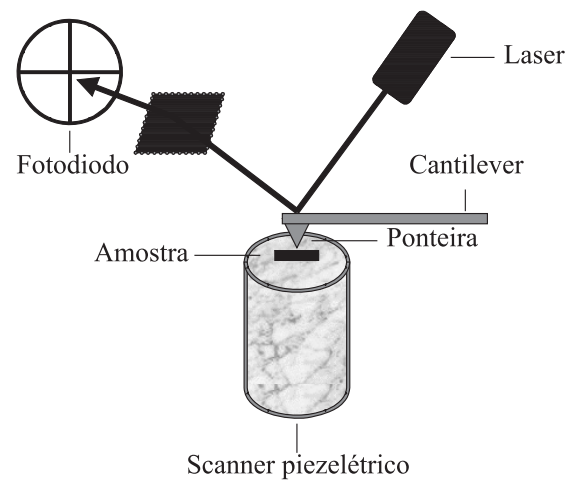

Figura 1. Diagrama esquemático do sistema de microscopia de força atômica

centenas de ângstrons da superfície da amostra e a força interatômica entre a ponta e a amostra é atrativa. Neste caso a ponta oscila em alta frequência (100 kHz a $1 \mathrm{MHz})$, a poucos nanômetros acima da superfície e a força total entre a ponta e a amostra é muito baixa, geralmente em torno de $10^{-12} \mathrm{~N}$. Esta oscilação aumenta consideravelmente a sensibilidade do microscópio, o que faz com que forças de van der Waals e forças eletrostáticas possam ser detectadas. $\mathrm{O}$ modo de não-contato não sofre os efeitos do atrito sobre a amostra, causada pela ponta, conforme é observado no modo contato após diversas varreduras. Por outro lado, este modo não tem encontrado aplicabilidade geral, devido à instabilidade entre a ponta e as forças adesivas da superfície e à resolução reduzida pela distância ponta-amostra que é relativamente grande. Esta limitação tem sido contornada com a utilização do modo intermitente.

O modo contato intermitente é similar ao não-contato, exceto pelo fato de que a ponta vibrante fica mais próxima da amostra, de forma que tenha um contato intermitente e é utilizado para contornar as limitações impostas pelo modo contato. A comparação das imagens nos modos contato e intermitente mostra que as superfícies são menos modificadas no modo intermitente.

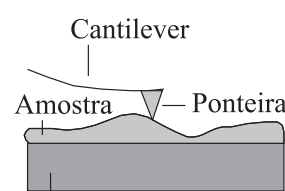

Substrato (a)

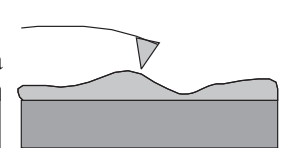

(b)

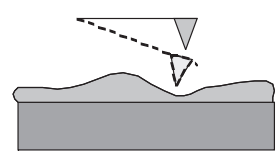

(c)
Figura 2. Representação esquemática dos modos de operação em AFM: (a) modo contato, (b) modo não-contato e (c) modo intermitente

Nos últimos anos, SPMs têm trazido notáveis contribuições à ciência, em especial à biologia, física, ciência dos materiais e microeletrônica. Em geral, os estudos com microscopia de força atômica podem ser divididos em aplicações topográficas e nãotopográficas. No primeiro grupo, o objetivo consiste em obter imagens da superfície da amostra para uma caracterização estrutural e dinâmica ${ }^{22-24}$. Em sistemas biológicos incluindo células, bactérias, vírus e biomoléculas, isso possibilita a compreensão dos fenômenos biofísicos/químicos envolvidos, constituindo-se em mais uma ferramenta auxiliar de análise e proporcionando um rápido desenvolvimento interdisciplinar ${ }^{25-32}$. Assim, é possível se obter novas informações sobre as bases moleculares dos processos biológicos, como por ex., a investigação de biofilmes bacterianos com superfícies metálicas em sistemas industriais ${ }^{33}$, situações clínicas e adsorção de moléculas protéicas em superfícies de biomateriais ${ }^{34}$.

Com a integração da AFM com a eletroquímica, desenvolveu- 
se a microscopia de varredura eletroquímica ("Scanning electrochemical microscopy - SECM") e tornou-se possível obter imagens simultâneas da topografia e atividade eletroquímica empregando a ponteira integrada ao cantilever. A ponteira atua simultaneamente como ultramicroeletrodo e sensor de força para imagem topográfica ${ }^{35,36}$.

A tecnologia advinda dos SPM permite estudar diretamente as forças entre átomos e moléculas em suas mais amplas variações, bem como forças de atrito, elétricas, magnéticas e químicas. $\mathrm{O}$ maior impacto dessa tecnologia é possibilitar a observação de estruturas em escala atômica no espaço real. Outra vantagem desse tipo de equipamento é sua capacidade de operar à temperatura ambiente, na presença de ar, o que reduz consideravelmente seu custo de construção e operação.

Grandes barreiras do conhecimento têm sido vencidas com o advento dos microscópios de varredura por sonda. A AFM tornouse uma importante técnica analítica em imunoensaios com aplicações topográficas e não-topográficas (biossensores baseados em cantilever) no estudo de processos biológicos, com habilidade para explorar os eventos biomoleculares em nível da interação entre as moléculas.

\section{ESTUDO TOPOGRÁFICO DA INTERAÇÃO ANTÍGENO- ANTICORPO}

As interações de reconhecimento molecular são eventos importantes nos aspectos biológicos ${ }^{37}$ e esta afinidade entre biomoléculas tem sido investigada nos últimos anos.

Os substratos mais comumente empregados nos estudos com AFM são vidro, mica e substratos à base de silício, que podem apresentar um filme metálico sobre a superfície. A superfície de mica é comumente utilizada para obtenção de imagens topográficas de proteínas por AFM devido ao caráter hidrofílico, ao fato de ser atomicamente plano e de possuir alta afinidade por moléculas protéicas. Para estudo de amostras biológicas é importante encontrar o método adequado de imobilização das moléculas no substrato e que não cause alteração estrutural do sistema. Vários trabalhos, envolvendo a modificação química de superfícies e imobilização de moléculas, foram desenvolvidos para obtenção de imagens topográficas de alta resolução da interação Ag-Ac com a técnica de AFM, através do monitoramento direto (sem a presença de marcadores).

Através de imagens topográficas, modo contato, BrowningKelley e colaboradores ${ }^{38}$ estudaram sistematicamente três complexos específicos de antígeno/anticorpo, soro albumina bovina (SAB) $50,0 \mu \mathrm{g} \mathrm{mL}^{-1}$ e proteínas purificadas de capsídio de vírus do tabaco (TMVCp 36,0 e TEVCp 7,9 $\mu \mathrm{g} \mathrm{mL}^{-1}$ ), com os respectivos anticorpos (IgG) específicos (anti-SAB IgG 17,96 mg mL ${ }^{-1}$, anti-TMVCp IgG 1,6 e anti-TEVCp IgG 2,0 mg $\mathrm{mL}^{-1}$ ). Uma imunoglobulina nãoespecífica de coelho foi empregada como controle experimental. A superfície de ouro, com rugosidade (rms) em torno de 2 a $5 \AA$, foi imersa em solução de $\mathrm{HS}\left(\mathrm{CH}_{2}\right)_{3} \mathrm{COOH} 1 \times 10^{-3} \mathrm{~mol} \mathrm{~L}^{-1}$ para formação da monocamada auto-organizada ("self-assembled monolayers”) através do grupo reativo tiol com o ouro. Após lavagem da superfície, adicionaram-se $20 \mu \mathrm{L}$ de cada amostra contendo os antígenos para formação do complexo $\mathrm{Ag}$-Ac através do - $\mathrm{COOH}$ terminal da molécula em diferentes concentrações e tempos de incubação ( 0,5 a 1,5 h) para os anticorpos. A simplicidade na preparação dos substratos, a interação dos antígenos com formação dos complexos na superfície de ouro modificada quimicamente e a facilidade de visualização individual dos antígenos, anticorpos e complexos Ag-Ac foram fatores importantes na realização do trabalho empregando AFM.

Outro grupo de pesquisadores, Ouerghi e colaboradores ${ }^{39}$, em- pregou a AFM, modo intermitente, para obter imagens topográficas de imunoglobulinas de coelho (Ag) e o respectivo complexo com o anticorpo (anti-IgG de coelho) imobilizado em superfície de mica atomicamente plana. Também investigaram a interação do Ag com anticorpo não específico, com utilização da varredura de superfície. Para preparação das amostras em superfície de mica não é necessária a modificação química para formação de monocamada auto-organizada. Sendo uma superfície atomicamente plana com características hidrofílicas e de alta afinidade por proteínas, as amostras de antígenos e de anticorpos para formação do complexo Ag-Ac foram adicionadas diretamente sobre a mica. $\mathrm{O}$ emprego da superfície de mica significa redução de custos e tempo na preparação das amostras para análise por AFM. Quist e colaboradores ${ }^{40}$ obtiveram imagens de antígenos, anticorpos e da formação do imunocomplexo específico por AFM, empregando moléculas de soroalbumina humana imobilizada e antisoroalbumina humana em superfície de mica. No trabalho de Ouerghi e colaboradores estudaram-se as interações específicas e não-específicas entre antígenos e anticorpos e, da mesma forma, Li e colaboradores ${ }^{41}$ investigaram a interação específica e nãoespecífica empregando AFM, modo intermitente, de dois complexos Ag-Ac: gonadotrofina coriônica humana (hCG)/monoclonal anti-hCG de camundongo e imunoglobulina de caprino (IgG)/ monoclonal anti-IgG de camundongo. Zhang e colaboradores ${ }^{42}$ estudaram a interação específica entre imunoglobulina humana (IgG) e anticorpo monoclonal anti-IgG em superfície de mica atomicamente plana, modo intermitente. Através de imagens topográficas, verificaram o número de ligações e a mudança conformacional durante a formação do complexo entre as moléculas de antígeno $\left(5 \times 10^{-3} \mathrm{~mol} \mathrm{~L}^{-1}\right)$ e proporções variáveis da concentração do anticorpo $\left(5 \times 10^{-3} \mathrm{~mol} \mathrm{~L}^{-1}\right)$.

Perrin e colaboradores ${ }^{43}$ demonstraram a habilidade da AFM em detectar e quantificar reações imunológicas específicas por meio de imagens topográficas. Foram investigadas duas reações imunológicas em substrato de óxido de silício modificado com grupos silanos: anticorpos anti-ferritina de camundongo e anti-Ac de camundongo conjugado com partículas de ouro coloidal, modo nãocontato, e a reação entre moléculas de ferritina (proteína presente no sangue humano) e anticorpos anti-ferritina, modo contato. As reações foram quantificadas diretamente, detectando-se o anticorpo anti-ferritina e o antígeno e monitorando-se a rugosidade da superfície do substrato ${ }^{44}$. Foi detectada uma concentração mínima de ferritina de $0,06 \mu \mathrm{g} \mathrm{mL}^{-1}$ e $0,3 \times 10^{-3} \mathrm{ng} \mathrm{mm}^{-2}$ de anticorpos antiferritina.

Outras superfícies podem ser empregadas nas investigações topográficas por AFM contendo antígenos e anticorpos imobilizados. Kooser e colaboradores ${ }^{45}$ empregaram AFM, modo intermitente, para confirmar o recobrimento de uma superfície de vidro com albumina de soro bovino (BSA) e anti-BSA, em diferentes tempos de incubação. Moloney e colaboradores ${ }^{46}$ empregaram anticorpos no reconhecimento de sítios de ligação do vírus de floresta Semliki (SFV) para subseqüiente obtenção de imagens topográficas por AFM, modo não-contato com o ar. Os anticorpos antiSFV (anti-E1 e anti-E2) foram imobilizados em superfície de silício via grupos silanos e ocorreu a formação do complexo com o antígeno SFV.

Através das imagens topográficas é possível observar o número de interações entre as moléculas de antígenos e anticorpos, a detecção de interações específicas e não-específicas (reatividade cruzada), a distinção entre classes de imunoglobulinas, bem como a geometria do imunocomplexo. A explicação dos sistemas complexos tem importância no estudo de uma variedade de interações $\mathrm{Ag}$-Ac e pode ser estendido a outros sistemas macromoleculares. 


\section{MONITORAMENTO DE IMUNOENSAIOS: CANTILEVER DO MICROSCÓPIO DE FORÇA ATÔMICA COMO TRANSDUTOR EM BIOSSENSOR}

Em adição ao estudo topográfico das biointerações, tornou-se possível a utilização de cantileveres como trandutores em áreas de contato de ordem nanométrica, em diferentes sensores onde um sinal químico é convertido em movimento mecânico com alta sensibilidade: sensor de força em AFM, sensor para temperatura, sensor para meio de viscoelasticidade, sensor de massa, sensor para tensão superficial e sensor para campo magnético ${ }^{13}$.

Quando o cantilever é empregado como sensor de força em AFM, com uma ponteira inserida em sua superfície, podem ser usadas curvas de distância para pesquisar as forças que contribuem para deflexão do cantilever (ou seja, forças de van der Waals e eletrostáticas) e as forças de adesão que atuam sobre a superfície celular podem ser mapeadas diretamente (Figura 3). Nos demais processos onde os cantileveres são empregados como sensores, a ponteira não é necessária.

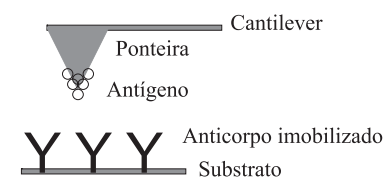

(a)

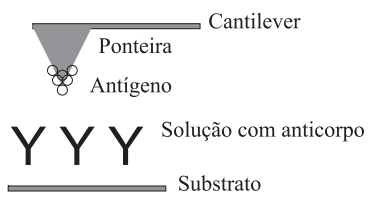

(b)
Figura 3. Cantilever do microscópio de força atômica como transdutor de biossensor. Ponteira modificada com antígeno e anticorpo imobilizado no substrato (a) ou presente em solução (b). O processo pode ser inverso, ou seja, o anticorpo pode estar imobilizado na ponteira do sensor

A força de interação é calculada pela lei de Hooke: $F=k \Delta z$, onde $F$ é força de interação, $\Delta z$ é deflexão do cantilever provocada pela interação e $k$, a constante elástica do cantilever, que depende de sua geometria e do material de construção. Diversos métodos de detecção têm sido propostos para medir esta deflexão (óptica, interferométrica, piezoresistividade) $)^{47} \mathrm{com}$ uma resolução da ordem de ângstrom. O esquema de deflexão óptica ${ }^{48}$ é o mais comumente empregado e uma de suas vantagens é a alta resolução sinalruído $^{49}$. O mecanismo óptico é capaz de detectar força entre $10^{-7} \mathrm{e}$ $10^{-12} \mathrm{~N}^{50}$ e sobre a superfície do transdutor tem sido aplicado um filme metálico (ouro, alumínio, por ex.) para intensificar a reflexão do laser no fotodiodo. À medida que ocorre um movimento vertical do mesmo, a posição do feixe de laser no fotodetector varia. $\mathrm{O}$ fotodetector pode medir deslocamentos de luz da ordem de alguns ângstrons. A razão entre o caminho de percurso da luz refletida ao fotodetector pelo comprimento do cantilever produz uma amplificação mecânica.

A ponteira mais comum em AFM é uma pirâmide cuja base é um quadrado ou um triângulo e está localizado na extremidade flexível do cantilever, responsável pelo sinal de transdução (Figura 3 ). Os cantileveres podem ter a forma de $\mathrm{V}$ ou de haste com diferentes comprimentos, espessuras e, usualmente, apresentam entre 23-300 $\mu \mathrm{m}$ de comprimento, $10-30 \mu \mathrm{m}$ de largura e 0,5-3 $\mu \mathrm{m}$ de altura $^{51}$. Transdutores de diferentes composições químicas estão disponíveis comercialmente, por ex., aqueles fabricados com silício, óxido de silício ou nitreto de silício $\left(\mathrm{Si}_{3} \mathrm{~N}_{4}\right)$ sendo o mais comumente empregado e com constante elástica entre 0,01 a 100 $\mathrm{Nm}^{-1}$. Atualmente, nanotubos de carbono para fabricação de ponteiras em AFM têm sido utilizados devido à alta resolução, pequeno diâmetro, estrutura bem definida e propriedades mecânicas e químicas adequadas $^{52}$. O mecanismo de transdução mecânica a partir de um sinal elétrico possibilita importantes vantagens, como precisão e sensibilidade, com resolução atômica do biossensor ${ }^{13}$. As forças de interações entre moléculas imobilizadas na ponteira com moléculas imobilizadas no substrato ou em meio líquido causam deflexões muito pequenas do cantilever, que são detectadas experimentalmente. Portanto, com a AFM é possível o monitoramento direto das forças de ligações estreptavidina-biotina ${ }^{53,54}$, da hibridização dos oligonucleotídeos complementares de $\mathrm{DNA}^{55}$ e nas interações antígeno-anticorpo, o que será discutido em detalhes.

A imobilização de moléculas na superfície da ponteira pode ser em monocamada auto-organizada (SAM) com grupos tióis $(-\mathrm{SH})^{56,57}$ sobre filme de ouro depositado ou por meio de grupos silanóis $(-\mathrm{SiOX})^{58}$ em substrato de silício. Outras técnicas podem ser empregadas para ativação das superfícies com propriedades químicas específicas, como a técnica sol-gel ${ }^{59}$ e deposição de polímeros por "spin coating" 60

Sensores baseados em microcantilever pelo $\mathrm{AFM}^{13,14}$ têm recebido uma maior atenção recentemente por apresentarem alta sensibilidade em área pequena $\left(\sim 100 \mu \mathrm{m}^{2}\right)$, quando comparados com superfícies de outros biossensores. A microscopia de força atômica tem sido empregada no monitoramento direto de interações específicas entre antígenos e anticorpos em um sistema de imunoensaio ${ }^{61}$.

Vários trabalhos envolvendo o desenvolvimento de biossensores baseados em cantilever no monitoramento de imunoensaios por AFM são destacados na literatura. Por meio desses experimentos podem-se obter informações da maneira que os anticorpos interagem com antígenos específicos, pois muitas vezes faltam dados sobre a estrutura e a termodinâmica dessas moléculas.

Dammer e colaboradores ${ }^{62}$ quantificaram forças específicas de interação entre albumina de soro bovino (SAB) conjugada com biotina e anticorpos policlonais anti-biotina. Para esses estudos empregaram duas superfícies de ouro, isto é, da ponteira e do substrato. Na ponteira do sensor (nitreto de silício com filme de ouro) foi imobilizada a SAB biotinilada e os anticorpos anti-biotina foram imobilizados em um substrato de ouro atomicamente plano, via ditio-bis-succinimidil undecanoato. A força de interação específica foi de $111,5 \pm 98,6 \mathrm{pN}$. Também determinaram forças nãoespecíficas no meio contendo $\mathrm{SAB}(17,5 \pm 26,5 \mathrm{pN})$, biotina $(33,8$ $\pm 22,5 \mathrm{pN})$, estreptavidina $(39,6 \pm 15,1 \mathrm{pN})$ e influência do $\mathrm{pH}$ na formação do complexo Ag-Ac.

Allen e colaboradores ${ }^{63}$ imobilizaram a ferritina em ponteira de $\mathrm{Si}_{3} \mathrm{~N}_{4}$ e o anticorpo anti-ferritina em substrato de silício via ativação das superfícies com glutaraldeído. Forças de interações AgAc foram detectadas na ordem de $49 \pm 10 \mathrm{pN}$. Esses trabalhos com albumina de soro bovino e ferritina demonstraram que a AFM pode ser aplicada nos estudos analíticos de interações entre moléculas envolvendo um sistema de biossensor e que o potencial da técnica de AFM está na obtenção de informações relacionadas às formas de interação entre moléculas de antígenos e anticorpos, através da detecção de forças.

O cantilever do microscópio de força atômica tem sido empregado nas investigações dos sítios de interações entre Ag-Ac em imunoensaios sobre superfícies. Hinterdorfer e colaboradores ${ }^{64}$ investigaram, através da AFM, as interações específicas entre o antígeno SAH (albumina de soro humano) imobilizado em superfície de mica e o anticorpo policlonal anti-SAH imobilizado na ponteira (nitreto de silício) via polietilenoglicol. O sensor permitiu a detecção da interação Ag-Ac com forças de $244 \pm 22$ pN. Com o desenvolvimento da metodologia foi possível detectar sítios antigênicos e estudar as forças dos fragmentos Fab do anticorpo.

Kim e colaboradores ${ }^{65}$ imobilizaram antígenos (peptídios) de receptores do órgão vomeronasal em superfícies de vidro (VN6 controle e VN7) e anticorpos anti-VN7 em esferas de poliestireno 
acopladas à ponteira do cantilever. Através do monitoramento das forças de interações $\mathrm{Ag}-\mathrm{Ac}$, a análise quantitativa do número de antígenos imobilizados na superfície de vidro pode ser estimada.

Stuart e Hlady ${ }^{66}$ estudaram o emprego da AFM no monitoramento das forças de interação Ag-Ac através da imobilização de antígenos conjugados com fluoresceína em esferas de vidro acopladas à sonda e de anticorpos $\operatorname{IgG}$ antifluoreceína em substrato de dióxido de silício modificados com reagentes silano e imidazol.

Raiteri e colaboradores ${ }^{67}$ estudaram as forças de interação do ácido 2,4-diclorofenoxiacético (2,4-D), herbicida comercial, com anticorpo monoclonal anti-2,4-D (5 e $\left.25 \mu \mathrm{g} \mathrm{mL}^{-1}\right)$. O cantilever $\left(\mathrm{Ni}_{3} \mathrm{~S}_{4}\right)$, com uma monocamada de ouro, foi incubado durante $2 \mathrm{~h}$ em solução aquosa de cistamina $\left(10 \mathrm{mg} \mathrm{mL}^{-1}\right)$ à temperatura ambiente e após lavagem com água foi incubado com glutaraldeído a $3 \%$ por mais $1 \mathrm{~h}$. A imobilização do antígeno $0,2 \mathrm{mg} \mathrm{mL}^{-1}(2,4-\mathrm{D}$ conjugado com albumina de soro bovino) foi durante $18 \mathrm{~h}$. A deflexão do cantilever foi monitorada empregando-se AFM, método óptico, anexada a uma célula em fluxo. O emprego de alta concentração do Ac não resultou em significativa deflexão do cantilever, porque provavelmente todos os sítios de ligação foram ocupados. Os resultados demonstraram que é necessária pequena quantidade de substâncias aplicada ao imunoensaio, mediante a sensibilidade do microcantilever.

É importante considerar que a determinação das forças de interação Ag-Ac empregando-se a ponteira em microscopia de força atômica não é decorrente apenas da deflexão do cantilever, mas também da interpretação dos dados adquiridos durante o monitoramento, que depende da natureza física do cantilever e da superfície de interação.

\section{CONCLUSÕES E PERSPECTIVAS}

A incorporação de microscopia de força atômica aos processos de análises químicas revela a importância dos estudos topográficos e do emprego de biossensores baseados em cantilever. A potencialidade da AFM é enfatizada pela obtenção de imagens das estruturas de biomoléculas ou biossuperfícies com resolução molecular; estudo das amostras em solução, ar, vácuo ou nitrogênio líquido com apreciável intervalo de temperatura; estudo de parâmetros que afetam os eventos em análise e estudo das propriedades químicas, físicas e mecânicas das superfícies (densidade, rigidez etc) e forças intermoleculares.

Os ensaios empregando AFM não requerem marcadores para monitorar interações entre antígenos e anticorpos. $\mathrm{O}$ monitoramento ocorre através da deflexão do cantilever do microscópio de força atômica (detecção mecânica) e isso resulta em vantagens como alta sensibilidade e limite de resolução em nível atômico, pequeno volume das amostras empregado nas análises e baixo tempo de análise.

Dentre os desenvolvimentos futuros, incluem-se a otimização de transdutores com dimensões e formas que apresentem baixo limite de detecção, com máxima sensibilidade e reprodutibilidade, desenvolvimento de software mais específico e emprego de um conjunto ("array") de cantileveres para reduzir o custo da análise.

A microscopia de força atômica não substitui o ELISA em laboratórios de análises clínicas, no entanto é uma importante ferramenta para diferenciar as reações específicas das reações cruzadas no imunoensaio.

\section{AGRADECIMENTOS}

À FAPESP pela bolsa concedida (Proc. 02/01176-0) e ao Prof. Dr. A. T. Adorno pela revisão gramatical.

\section{REFERÊNCIAS}

1. Turner, A. P. F.; Karube, I.; Wilson, G. S.; Biosensors: fundamentals and applications, Oxford University Press: Oxford, 1989.

2. Fatibello Filho, O.; Capelato, M. D.; Quim. Nova 1992, 15, 28.

3. Babkina, S. S.; Vinter, V. G.; Zainullina, A. S.; J. Anal. Chem. 1994, 49,1188 .

4. Gil, E. S.; Kubota, L. T.; Yamamoto, Y. I.; Quim. Nova 1999, 22, 874.

5. Issert, V.; Grenier, P.; BellonMurel, V.; Sciences des Aliments 1997, 17,131.

6. Rosatto, S. S.; Freire, R. S.; Duran, N.; Kubota, L. T.; Quim. Nova 2001, $24,77$.

7. Morgan, C. L.; Newman, D. J.; Price, C. P.; Clin. Chem. 1996, 42, 193.

8. Riccardi, C. S.; Costa, P. I.; Yamanaka, H.; Quim. Nova 2002, 25, 316.

9. Ferreira, A. A. P.; Colli, W.; Costa, P. I.; Yamanaka, H.; Biosens. Bioelectron. 2005, 21, 175

10. Wilson, G. S.; Alwis, U.; Anal. Chem. 1987, 59, 2786.

11. Gascón, J.; Oubiña, A.; Ballesteros, B.; Barceló, D.; Camps, F.; Marco, M. P.; Gonzalez Martinez, M. A.; Anal. Chim. Acta 1997, 347,149.

12. Santos, N. C.; Castanho, M. A. R. B.; Biophys. Chem. 2004, 107, 133.

13. Raiteri, R.; Grattarola, M.; Butt, H.-J., Skládal, P.; Sens. Actuators, B 2001, 79, 115.

14. Ziegler, C.; Anal. Bioanal. Chem. 2004, 379, 946.

15. Binnig, G.; Rohrer, H.; Sci. Am. 1985, 253, 40.

16. Chichester, B. L.; Procedures in Scanning Probe Microscopies, John Wiley \& Sons, Inc.: England, 1998.

17. Scanning Probe Microscopy Training Notebook, Digital Instruments, 1998.

18. Bustamante, C.; Keller, D.; Phys. Today 1995, 48, 32

19. Ohnesorge, F.; Binnig, G.; Science 1993, 260 , 1451.

20. Howland, R.; Benatar, L.; A Pratical Guide to Scanning Probe Microscopy, Park Scientific Instruments, 1996.

21. Worcester, D. L.; Miller, R. G.; Bryant, P. J.; J. Micros. 1988, $152,817$.

22. Sangwal, K.; Servat, J.; Sanz, F.; Torrentburgues, J.; J. Cryst. Growth 1997, $180,263$.

23. Caro, J.; Gorostiza, P.; Sanz, F.; Fraxedas, J.; Synth. Met. 2001, 121, 1417.

24. Benitez, J. J.; Kopta, S.; Dies-Perez, I.; Sanz, F.; Ogletree, D. F.; Salmeron, M.; Langmuir 2003, 19, 762.

25. Li, M. Q.; Appl. Phys. A: Mater. Sci. Process. 1999, 68, 255.

26. Merino, S.; Domenech, O.; Diez, I. Sanz, F.; Vinas, M.; Montero, M. T. Hernández-Borrell, J.; Langmuir 2003, 19, 6922.

27. Brett, A. M. O.; Chiorcea, A. M.; Langmuir 2003, 19, 3830.

28. Allen, S.; Rigby-Singleton, S. M.; Harris, H.; Davies, M. C.; O'Shea, P.; Biochem. Soc. Trans. 2003, 31, 1052.

29. Shao, Z. F.; Mou, J.; Czakowsky, D. M.; Yang, J.; Yuan, J. Y.; Adv. Phys. 1986, 45,1 .

30. Gomez, E.; Valles, E.; Gorostiza, P.; Servat, J.; Sanz, F.; J. Electrochem. Soc. 1995, 142, 4091.

31. Gorostiza, P.; Diaz, R.; Servat, J.; Sanz, F.; Morante, J. R.; J. Electrochem. Soc. 1977, 144, 909.

32. Bevilaqua, D.; Diez-Perez, I.; Fugivara, C. S.; Sanz, F.; Garcia, O.; Benedetti, A. V.; J. Braz. Chem. Soc. 2003, 14, 637.

33. Beech, I. B.; Smith, J. R.; Steele, A. A.; Penegar, I.; Campbell, S. A.; Colloids. Surf., B 2002, 23, 231.

34. Lu, X. Y.; Huang, Y.; Qian, W. P.; Tang, Z. M.; Lu, Z. H.; J. Biomed. Mater. Res. A 2003, 66, 722 .

35. Macpherson, J. V.; Unwin, P. R.; Anal. Chem. 2001, 73, 550.

36. Hirata, Y.; Yabuki, S.; Mizutani, F.; Bioelectrochemistry 2004, 63, 217.

37. Lim, K.; Herron, J. N.; Biochemistry 1995, 34, 6962.

38. Browning-Kelley, M. E.; WaduMesthrige, K.; Hari, V.; Liu, G. Y.; Langmuir 1997, 13, 343 .

39. Ouerghi, O.; Touhami, A.; Othmane, A.; Ben Quada, H.; Martelet, C.; Fretigny, C.; Jaffrezic-Renault, N.; Sens. Actuators, B 2002, 84, 167.

40. Quist, A. P.; Bergman, A. A.; Reimann, C. T.; Oscarsson, S. O.; Sundqvist, B. U. R.; Scanning Microscopy 1995, 9, 395.

41. Li, L. Y.; Chen, S. F.; Oh, S. J.; Jiang, S. Y.; Anal. Chem. 2002, 74, 6017.

42. Zhang, P. C.; Bai, C.; Ho, P. K. H.; Dai, Y.; Wu, Y. S.; IEEE Eng. Med. Biol. 1997, 16, 42 .

43. Perrin, A.; Lanet, V.; Theretz, A.; Langmuir 1997, 13, 2557.

44. Vassault, A.; Azzedine, M. C.; Bailly, M.; Cam, G.; Ann. Biol. Clin. 1986, $44,686$.

45. Kooser, A.; Manygoats, K.; Eastman, M. P.; Porter, T. L.; Biosens. Bioelectron. 2003, 19, 503

46. Moloney, M.; McDonnell, L.; O Shea, H.; Ultramicroscopy 2002, 91, 275.

47. Magonov, S. N.; Whangbo, M.-H.; Surface Analysis with STM and AFM, VCH: New York, 1996.

48. Meyer, G.; Amer, N. M.; Appl. Phys. Lett. 1988, 53, 1045.

49. Gustafsson, M. G. L.; Clarke, J.; J. Appl. Phys. 1994, 76, 172.

50. Muller, D. J.; Anderson, K.; Trends Biotechnol. 2002, 20, S45. 
51. Colton, R. J.; Baselt, D. R.; Dufrêne, Y. F.; Green, J.-B. D.; Lee, G. U.; Curr. Opin. Chem. Biol. 1997, 1, 370.

52. Woolley, A. T.; Cheung, C. L.; Hafner, J. H.; Lieber, C. M.; Chem. Biol. 2000, 7, R193.

53. Florin, E.-L.; Moy, V. T.; Gaub, H. E.; Science 1994, 264, 415.

54. Lee, G. U.; Kidwell, D. A.; Colton, R. J.; Langmuir 1994, 10, 354.

55. Lee, G. U.; Chrisey, L. A.; Colton, R. J.; Science 1994, 266, 771.

56. Horácek, J.; Skládal, P.; Anal. Chim. Acta 1997, 347, 43.

57. Sato, F.; Okui, H.; Akiba, U.; Suga, K.; Fujihira, M.; Ultramicroscopy 2003, 97, 303.

58. Weetall, H. H.; Methods Enzymol. 1976, 44, 134.

59. Brinker, C. J.; Scherer, G. W.; Sol-Gel Science: The Physics and Chemistry of Sol-Gel Processing, Academic Press: San Diego, 1990.

60. Betts, T. A.; Tipple, C. A.; Sepaniak, M .J.; Datskos, P. G.; Anal. Chim. Acta 2000, 422, 89.
61. Alvarez, M. C.; Tamayo, J.; Lechuga, L. M.; Abad, A.; Montoya, A.; Biosens. Bioelectron. 2003, 18, 649.

62. Dammer, U.; Hegner, M.; Anselmetti, D.; Wagner, P.; Dreier, M.; Huber, W.; Guntherodt, H. J.; Biophys. J. 1996, 70, 2437.

63. Allen, S.; Chen, X.; Davies, J.; Davies, M. C.; Dawkes, A. C.; Edwards, J. C.; Roberts, C. J.; Sefton, J.; Tendler, S. J. B.; Williams, P. M.; Biochem. 1997, 36, 7457.

64. Hinterdorfer, P.; Baumgartner, W.; Gruber, H. J.; Schilcher, K.; Schindler, H.; Proc. Natl. Acad. Sci. U.S.A. 1996, 93, 3477.

65. Kim, H.; Tsuruta, S.; Arakawa, H.; Osada, T.; Ikai, A.; Ultramicroscopy 2004, 100, 203.

66. Stuart, J. K.; Hlady, V.; Colloids Surf., B 1999, 15, 37.

67. Raiteri, R.; Nelles, G.; Butt, H. J.; Knoll, W., Skladal, P.; Sens. Actuators, $B$ 1999, 61, 213. 